\author{
М.В. Суворова
}

\title{
СЕТЕВАЯ ИННОВАЦИОННАЯ ДЕСТРУКТИВНОСТЬ НЕСОВЕРШЕННОЛЕТНИХ В СОВРЕМЕННОМ МИРЕ
}

\begin{abstract}
Аннотация. Предметом исследования являются психологические состояния несовершеннолетних с учётом того, что современный мир становится всё могущественней в инновационных технологиях. Трудно представить деятельность человека, из которой полностью исключён компьютер. Нельзя отрицать, что технологические инновации сегодняшней жизни несут в себе развитие, а, следовательно, новые возможности в различных отраслях необходимых для общества. Но достигая вершин, человечество столкнулось с так называемым побочным эффектом, выявляющимся на подрастающем поколении. Компьютерная зависимость наносит огромный и непоправимый вред, поражая психику молодёжи. Методом исследования является изучение научной литературы с целью анализа и выявления научной новизны причин отклоняющегося поведения несовершеннолетних, связанных с компьютерными инновациями. Основным выводом является то, что на фоне десрормированного психического пространства происходит формирование делинквентного поведения. Противоправное поведение несовершеннолетнего по своей сути означает наличие внутреннего конфликта, а так же наличие конфликта между личностью и обществом - между индивидуальными стремлениями и общественными интересами. Далее необходимо отметить, что деструктивное поведение несовершеннолетних возникает в результате внутреннего желания удовлетворить свои потребности, что означает изменить психологическое неравновесие на психологическое равновесие, несмотря на общественное мнение.
\end{abstract}

Ключевые слова: чувство удовлетворения собой, зависимое поведение, психическое развитие, эмоции гнева, воспитание, патологическое влечение, страх, агрессия, несовершеннолетний, игровая зависимость.

Abstract. The subject of the research is the psychological state of minors, bearing in mind that the modern world is becoming more powerful in innovative technologies. It is difficult to imagine human activity from which the computer is completely excluded. It is undeniable that technological innovation of life to But reached the top, humanity is faced with the so-called side effects, are identified at the younger generation. Computer addiction is doing great and irreparable harm, affecting the psyche of young people. The research methodology is the study of scientific literature in order to analyze and identify the causes of scientific novelty of deviant behavior of minors related to computer innovations. The main conclusion is that against the background of strained mental space is the formation of delinquent behavior. Unlawful conduct of a minor in nature means that there is an internal conflict, as well as a conflict between the individual and society - between individual aspirations and the public interest. Further, it should be noted that the destructive behavior of minors is the result of an internal desire to meet their needs, which means to change the psychological imbalance to psychological balance, in spite of public opinion.

Key words: a sense of satisfaction, dependent behavior, mental development, upbringing, emotions of anger, craving, fear, aggression, minor, game addiction.

\section{Чувство войны}

За всю историю существования человечества на планете Земля нам известно огромное множество и разнообразие войн. Все военные стремления наших предков сводились к идеям и территориям. Изучая исторически сложившиеся события, сегодня человек разумный Нomo sapiens может с уверен- ностью сказать, что не все разногласия можно решать военными действиями, внося в человеческий разум изменённое состояние сознания, меняя его жизненные ценностные ориентиры. Естественно, под словом «война» подразумевается некая сила, способная что-то либо изменить в сторону сильнейшего. В военном деле существуют две силы сила разрушения и сила стратегии, что относится 


\section{Профессиональная психология}

к искусству военных действий с древних времён до настоящего времени. Но как бы человечество не причисляло войну к необходимости достижения сложной цели, этот феномен отнюдь не добродетелен, даже если несёт в себе характер освобождения от гнёта. Ф.Е. Дзержинский писал, что уловить и понять сущность жизни настоящего человека может только тот, кто чувствует красоту. А что способен уловить и понять тот, кто чувствует холодное оружие в своих руках и чужую горячую кровь на своём лице? Несомненно, даже в воображении проживая такие мгновения в душе проносятся чувства страха и агрессии, особенно пропитанное всё это идеей свободы и защитой своих близких!

\section{Мнения учёных о страхе и гневе}

Выдающийся психолог С.С. Томкинс полагал, что нейрофизиологические механизмы реакции испуга и возбуждения схожи с механизмами, лежащими в основе эмоции страха, и часто являются его активаторами. Он считал, что базовая взаимосвязь между эмоциями интереса, удивления и страха также обусловлена сходством их нейрофизиологическими механизмами, а частичное освобождение от страха вызывает возбуждение [2].

По мнению американского психолога К.Э. Изарда, интенсивный страх существенно ограничивает восприятие, мышление и свободу выбора индивида, так как создаёт эффект «туннельного восприятия», соответственно ограничивает и свободу поведения человека. Испытывая страх, человек перестаёт принадлежать себе, им движет одно единственное стремление - устранить угрозу, избежать опасности [2]. Некоторые объекты и ситуации психиатр Джон Боулби называет естественными активаторами страха, так как с большей силой, чем другие сигнализируют нам об опасности. К ним относятся боль, одиночество, необычность объекта, внезапное приближение объекта, внезапное изменение ситуации и, возможно, высота. По сути это механизмы, готовящие человека к восприятию возможной угрозы и следственно к действию для успешного освобождения путём возбуждения, служащие адаптации и выживанию [1].

Однако страх взаимодействует с эмоцией гнева, что определяет поведение человека в определённых ситуациях, так как с помощью данной эмоции он может устранить барьеры для преодоления желанной цели. Именно чувство физической и психологической несвободы вызывает гнев, направленный на его источник. Особенно старшие дети и подростки реагируют более бурно на невербальные ограничения и запреты, чем на физическую несвободу. При отвлечении человека посторонним вопросом, который с головой погружён в решение какой-либо ситуации или задачи, можно вызвать эмоцию гнева, так как происходит ограничение свободы деятельности человека, что является препятствием к достижению желанной цели.

\section{Роль окружающей среды для несовершеннолетнего в формировании деструкций}

Для несовершеннолетнего как растущего и развивающегося организма очень важно соблюдение условий, в которых он имеет возможность развиваться полноценно и гармонично. Учитывая периодизацию развития человека, родителю или лицу, исполняющему эту роль, необходимо просвещаться об особенностях развития своего ребёнка как физических, так и психических. Вооружившись знаниями «воспитатель-родитель» сможет заметить изменения, происходящие с несовершеннолетним, так называемые характерологические последствия (внутренняя несвобода - стеснительность или внутренняя хаотичность, отсутствие навыков самоконтроля - несдержанность, агрессивность), т.е. результат неправильного воспитания, что позволит взрослому скорректировать собственное поведение, а соответственно и поведение ребёнка. Поскольку многие поведенческие проявления имеют место в результате взросления, поэтому требуют знаний, умений дифференциации нормы и патологии для предотвращения деструктивных изменений личности.

Физические и психические потребности в формировании личности ребёнка должны восполняться своевременным и грамотным воспитанием, в противном случае образуются «дыры или пробоины» в структуре личности, заполняющиеся негативом и ведущие к девиантности. Природа человека такова, что в любом возрасте ему необходимо испытывать чувство собственного удовлетворения и эмоции удовольствия как духовные - любовь родителей, образование, организованный досуг, т.е. психическое развитие, так и физические - утоление голода, материнская ласка и т.д. Образование «дыр или пробоин» происходит из-за недостаточного и деформированного влияния окружающей среды на детский развивающийся каждый день организм.

В учении австрийского психоаналитика, психиатра и невролога Зигмунда Фрейда говорится об инстинкте смерти или влечении к смерти (деструкции, агрессии, ненависти, уничтожении, разрушении, убийства), который трактовался как 


\section{Психология и психотехника 10(97) • 2016}

один из двух основных человеческих инстинктов, противостоящий инстинкту жизни, сексуальности и самосохранения. По мнению 3. Фрейда, инстинкт деструкции «работает в каждом живом существе и стремится привести его к распаду, вернуть жизнь в состояние «неживой материи». Со всей серьёзностью он заслуживает названия «инстинкт смерти», в то время как эротические влечения представляют собой стремление к жизни. Инстинкт смерти становится инстинктом деструкции, когда он направлен во вне, на объекты с помощью специальных органов. Живое существо, так сказать, сохраняет свою собственную жизнь, разрушая чужую. Но часть инстинкта смерти остаётся деятельной внутри живого существа, и нами прослежено достаточно большое число нормальных и патологических проявлений направленного внутрь инстинкта деструкции» [3].

Немецкий психолог, психоаналитик Эрих Фромм утверждал в своей концепции, что деструкция является страстью, которая корнями уходит в целостную структуру человеческого бытия, а не инстинктивное влечение. Деструкции не может быть у животного, ибо она по природе своей коренится в «человеческой сущности» и относится к возможности, придающей смысл жизни. Э. Фромм считал, что проблема состоит в выяснении, насколько специфические условия существования человека ответственны за возникновение изменений в психике [4].

Из выше сказанных разных мнений учёных можно прийти к одному мнению о существовании некой внутренней энергии человека, как живого существа, врождённой или приобретённой, т.е. инстинкт или страсть, которая направляется на самого себя, а также на других живых существ. Сила данной энергии может быть разрушительной и созидательной в зависимости от влияния окружающей среды. В нашем случае мы рассматриваем развивающийся детский организм, который, подобно ростку, нуждается в физическом и психическом грамотном подходе (благополучие семейного института и семейного воспитания, заинтересованность школы в сохранении и вовлечении в активный учебный процесс каждого ученика, особенно когда к нему нужен особый подход, способность школы стать инструментом компенсации недостатков семейного воспитания, активным предупреждением преступлений со стороны своих учеников). Поэтому «дыры или пробоины» образовавшиеся в психическом пространстве несовершеннолетнего можно назвать искажениями целостности, имеющие свойство наполняться патологическими явлениями. Можно отметить, что они не просто наполняют психическое пространство, но и создают его.

На фоне данной деформации в структуре психики и деятельности могут появляться патологические влечения. Влечение - это стремление к удовлетворению потребностей. Оно базируется на базе безусловных рефлексов. К базовым потребностям относятся пищевой и половой (продление рода), а так же оборонительный (обеспечивающий сохранение жизни). Нарушение влечений может быть отражением ослабленности волевой, мотивационной психической активности в результате различных причин (органические нарушения ЦНС, состояния опьянения, педагогическая запущенность и т.д.). В жизни человека инстинкты играют существенную роль, с возрастом они подвергаются контролю волевой деятельности. Поэтому, нарушение инстинктивных реакций, прежде всего, формируется у детей и подростков.

\section{Замена живого интерактивного воспитания компьютерным}

Патологическое влечение (тяга) - это специфическая интенция к объекту зависимости, возникающая посредством активизации в памяти аффективно заряженного положительного впечатления и одновременное осознание отсутствия данного состояния сейчас, приводящая к стремлению воспроизвести его в ближайшем будущем [5].

Зависимое поведение определяется как внешние действия детей и подростков, связанные с непреодолимым влечением к объекту, другими словами оно обусловлено психической зависимостью от него. Объект зависимости одновременно является средством удовлетворения потребностей, лежащих в основе влечения и ведущим мотивом деятельности. Причиной формирования зависимого поведения является особая привлекательность объекта влечения для ребёнка. По истечению времени взаимодействия с объектом влечение возрастает и становится непреодолимым, что проявляется потерей контроля над поведением. Суть зависимого поведения лежит в отношении несовершеннолетнего у самому себе, другим и окружающему миру, определяющее способы удовлетворения базовых потребностей. По мере разрешения конфликтов между стремлением несовершеннолетнего к удовольствию и необходимостью адаптированного существования в социуме (учитывать свои перспективные интересы и интересы других людей или общества), служащие адекватной оценке своего поведения можно отслеживать динамику формирования зависимого поведения. 


\section{Профессиональная психология}

Многофункциональность данного поведения позволяет по мере развития влечения менять доминирующую функцию:

- познавательная (удовлетворение любопытства, изменение восприятия, расширение сознания);

- гедоническая (получение удовольствие);

- психотерапевтическая (релаксация при наличии стрессовых ситуаций или эмоционального напряжения, повышения уровня комфортности, снятие барьеров в поведении, которое пугает);

- компенсаторная (замещение проблемного функционирования в сфере общения, развлечений);

- стимулирующая (повышение продуктивности деятельности);

- адаптационная (приспособление к группе сверстников);

- анестетическая (избегание боли).

Зависимое поведение по мере развития всё больше фокусируется на влечении, всё остальное (пусковой механизм влечения) остаётся на периферии [6].

На сегодняшний день современный мир представляет собой период бурного развития информационных технологий. Современные дети не представляют свою жизнь без компьютера. Это является достаточно серьёзной проблемой, так как компьютерные игры вызывают зависимость аналогичную наркотической. Глобализация проблемы состоит в том, что компьютер в жизни несовершеннолетнего занимает по значимости первое место.

Компьютерная зависимость у подростков патологическое пристрастие к компьютеру с максимальным времяпровождением за ним, ведущая к изменению в психике. Подростков привлекают виртуальные и онлайн игры. Они создают ощущение соревновательного эффекта, формирующий азарт. В играх ребёнок может быть гораздо успешен, чем в реальной жизни, поэтому быстро формируется пристрастие у компьютеру. Очень опасны ролевые игры для внушаемых детей, т.е. со слабой нервной системой, так как они копируют поведение героев. Поскольку компьютерное пристрастие возникает в психике ребёнка в месте «дыр и пробоин» психического пространства, то это означает нахождение выхода из неразрешённых ситуаций в реальности путём подражания негативным персонажам и даже «кровавым», в качестве мести и защиты. Учитывая качество современных игр, создаётся опасность, что у личности с низким уровнем критичности исчезает грань между её имитацией и реальностью.
Проявления игромании выражается в увеличении времяпровождения за монитором, отказ от реального общения с друзьями, скрытность, тотальное игровое погружение, неспособность себя контролировать, игровая замена еды и сна, эмоциональный подъём во время игры, забывание об учёбе и других важных событиях. Самым ярким проявлением является синдром отмены - отсутствие возможности сесть за монитор вызывает ярость, гнев, агрессию, замкнутость, плач.

По мнению исследователей, в психологической науке несовершеннолетние с игровой зависимостью склонны к девиантному поведению (нарушению норм и правил, самоповреждающему, аддиктивному и делинквентному поведению) и обладают низким показателем волевого контроля эмоциональных реакций. Для разрешения подростками реальных трудных жизненных ситуаций ими применяются неконструктивные копинг-стратегии, главной функцией которых является разрешение проблемы, а не функция регулирования негативных эмоциональных состояний, связанными с неудовлетворёнными потребностями в общении, самоутверждении и т.д. [7].

Для подростка важно каким-либо способом заявить о себе и продемонстрировать плоды своей активности. Если реализовать это не удаётся, то появляется деструктивное поведение. Компьютерные игры несущие боевой настрой, основанные на уничтожении противника, соответственно на победе отличное средство самовыражения пусть даже виртуального для несостоявшейся полной активности в реальной жизни несовершеннолетнего. Сетевое общение и свобода действий, разных эмоций, острые ощущения, отстаивание собственной позиции среди других, таких же, как он игроков, куда более приятней выяснения отношений в трудный для него период взросления с не понимающими родителями и педагогами. Во время игровой деятельности, особенно успешной, сложившийся внутренний конфликт устраняется, ребёнок испытывает удовлетворение собой, что способствует закреплению желания пребывать всё дольше в игре и деструктивное поведения как следствие компьютерной абстиненции, нарушение внутреннего комфортного пребывания «Я» при лишении виртуальной жизни. Столкнувшись с такой проблемой родителям необходимо задуматься, что в жизни ребёнка породило такую неадекватную реакцию и постараться изменить эти неблагоприятные условия.

Большую опасность в реальной жизни несовершеннолетнего представляют копинг-стратегии компьютерных игр с применением одобряемых бо- 


\section{Психология и психотехника 10(97) • 2016}

евых действий для достижения цели, имеющие прямое влияние на ещё формировавшуюся психику.

\section{Механизм деструктивности}

Основатель гештальт - терапии Фредерик Пёрлз в своих работах уделил внимание такому процессу, который в науке определяется как гомеостаз. Учёный подчёркивал, что этот процесс непрерывный, благодаря которому происходит приспособление или адаптация путём саморегуляции, ведущей к психологическому равновесию. Поскольку постоянные потребности являются психологическими по своей природе, то они удовлетворяются посредствам гомеостатических приспособительных механизмов, другими словами «психологической стороной гомеостатического процесса». Организму необходимы психологические контакты, поэтому нарушение психологического равновесия регулируется поведением человека, т.е. направлением деятельности и интенсивностью на удовлетворение потребностей [8].

Нельзя не отметить и роль вегетативной нервной системы (ВНС) в организме человека. Необходимо помнить, что вегетативная нервная система в поддержании постоянства внутренней среды (гомеостаза), а так же в приспособительных реакциях при изменениях окружающей среды играет ведущую роль. ВНС влияет на физическую и на психическую деятельность человека, принимая участие во многих поведенческих актах, которые осуществляются под управлением головного мозга и является не контролируемой сознанием и волей человека [9].

Учитывая, что в психике человека относительную самостоятельность человеческих реакций и действий обусловливает наличие сознания, подсознания и бессознательного, т.е. - бессознательно-инстинктивные, врождённые реакции; импульсивно-реактивные, малоосознанные эмо- циональные реакции; - привычно-автоматизированные подсознательные действия; действия-навыки; - сознательно-волевые действия, которые являются ведущими во взаимодействии человека со средой, можно понимать и оценивать человеческое поведение. Важное значение имеет импульсивно-эмоциональная сфера человека, находящиеся в подкорковой системе головного мозга, где формируются неосознаваемые желания, его влечения, установки и страсти. Подсознательный уровень психики имеет автоматизмы, т.е. стереотипные действия в определённых ситуациях, которые загружаются в сознание для оптимальной деятельности человека, другими словами набор готовых поведенческих штампов для регуляции собственной деятельности [10].

\section{Вывод}

Из анализа изученных источников можно сделать вывод, что в результате асоциального воздействия на человека обществом (одним субъектом или группой) или любых других негативных факторов происходит деформация психологического равновесия, что является сигналом нервной системы о неблагополучии и влечёт за собой острое желание любым путём его восстановить. Подобное непреодолимое острое желание выплескивается или имеет свой выход путём изменений в поведении, отклоняющихся от нормы, так как воздействие воспринимается субъектом как нарушение комфортного места дислокации (в обществе, группе, семье и т.д.). Изменения проявляются от ситуативного поведения до неврозов и серьёзных психических расстройств. Способ достижения постоянства психологического или душевного равновесия напрямую зависит от ущербности личности, жизненных ценностей и социальной среды обитания, чем непосредственно обусловлено и детерминируется его поведении.

\section{Список литературы:}

1. Боулби Дж. Привязанность. М.: Гардарики, 2003. 480 с.

2. Изард К.Э. Психология эмоций. СПб.: Питер, 1999. 464 с.

3. Фрейд 3. Психоанализ. Религия. Культура. М.: Канон+, 2014. 368 с.

4. Фромм Э. Анатомия человеческой деструкции / Пер. с англ. Э.М. Телятникова, Т.В. Панфилова. М., 1973.316 с.

5. Журнал практической психологии и психоанализа. 2009. № 2. [Электронный ресуpc] URL: http://psyjournal.ru/index.php.

6. Шабалина В.В. Зависимое поведение школьников. СПб.: Медицинская пресса, 2001. 176 с.

7. Мураткина Ю.Н. Взаимосвязь компьютерной зависимости и совладающего поведения подростков: Дисс. ... канд. психол. наук (19.00.07). Сургут, 2010. 154 с.

8. Пёрлз Ф. Практика гештальт-терапии / Пер. М.П. Папуш. М.: Институт общегуманитарных исследований, 2005. [Электронный ресурc] URL: http://www.psychol-ok.ru/lib/perls_f/gp/gp_03.html.

9. Вегетативная нервная система. [Электронный ресурc] URL: https://ru.wikipedia.org/wiki/.

10. Баданина Л.П. Основы общей психологии: учебное пособие // ЛитМир. [Электронный pecypc] URL: https://www. litmir.me $/ \mathrm{bd} / \mathrm{lb}=536752$. 


\section{Профессиональная психология}

\section{References (transliterated):}

1. Boulbi Dzh. Privyazannost'. M.: Gardariki, 2003. $480 \mathrm{~s}$.

2. Izard K. E. Psikhologiya emotsii. SPb.: Piter, 1999. 464 s.

3. Freid Z. Psikhoanaliz. Religiya. Kul'tura. M.: Kanon+, 2014. $368 \mathrm{~s}$.

4. $\quad$ Fromm E. Anatomiya chelovecheskoi destruktsii / Per. s angl. E.M. Telyatnikova, T.V. Panfilova. M., 1973. 316 s.

5. Zhurnal prakticheskoi psikhologii i psikhoanaliza. 2009. № 2. [Elektronnyy resurs] URL: http://psyjournal.ru/index.php.

6. Shabalina V.V. Zavisimoe povedenie shkol'nikov. SPb.: Meditsinskaya pressa, 2001. $176 \mathrm{~s}$.

7. Muratkina Yu.N. Vzaimosvyaz' komp'yuternoi zavisimosti i sovladayushchego povedeniya podrostkov: Diss. ... kand. psikhol. nauk (19.00.07). Surgut, 2010.154 s.

8. Perlz F. Praktika geshtal't-terapii / Per. M.P. Papush. M.: Institut obshchegumanitarnykh issledovanii, 2005. [Elektronnyy resurs] URL: http://www.psychol-ok.ru/lib/perls_f/gp/gp_03.html.

9. Vegetativnaya nervnaya sistema. [Elektronnyy resurs] URL: https://ru.wikipedia.org/wiki/.

10. Badanina L.P. Osnovy obshchei psikhologii: uchebnoe posobie // LitMir. [Elektronnyy resurs] URL: https://www.litmir.me/ $\mathrm{bd} / ? \mathrm{~b}=536752$. 